\section{ATYR2810 AN ANTI-NRP2 MONOCLONAL ANTIBODY TARGETS TUMOR-ASSOCIATED MACROPHAGES}

Samantha Tyler*, Michaela Ferrer, Erik Escobedo, Kaitlyn Rauch, Sofia Klopp-Savino, Justin Rahman, Zhiwen Xu, Esther Chong, Suzanne Paz, Leslie Nangle. aTyr Pharma, San Diego, CA, United States

Background Neuropilin-2 (NRP2) is a single transmembrane pleiotropic receptor that utilizes co-receptors for signal transduction and is known to impact tumor progression and metastasis. $^{1}$ Deletion of NRP2 in murine tumor-associated macrophages (TAMs) downregulated several immunosuppressive and tumor-promoting genes and upregulated immune-stimulatory genes in the myeloid compartment. ${ }^{2}$ However, little is known about the role of NRP2 in human TAMs. We previously reported significant expression of NRP2 on TAMs derived from triple negative breast cancer (TNBC), ${ }^{3}$ and demonstrated the ability of ATYR2810, a monoclonal anti-NRP2 antibody, to regulate epithelial-mesenchymal transition (EMT) genes, such as the transcription factor ZEB1, and to enhance chemotherapeutic efficacy for aggressive breast cancer. ${ }^{4}$ Knowing TAMs play an important role in EMT transition and therapy resistance of cancer, and also rely on ZEB1 for their cancer promoting roles such as immune regulation, ${ }^{5}$ we sought to investigate the effects of ATYR2810 on TAMs.

Methods MDA-MB-231 TAMs were generated from monocytes in the presence or absence of ATYR2810. TAM phenotypes, gene expression and ability to secrete cytokines were assessed by flow cytometry, qRT-PCR and MSD respectively. TAM suppressive-ness was measured in co-culture experiments. $\mathrm{T}$ cell proliferation and activation markers were monitored by flow cytometry and cytokine production by MSD.

Results NRP2 is highly expressed on TAMs, which suppress T cell proliferation, activation and cytokine release. When differentiated in the presence of ATYR2810, a significant decrease in their suppressive capabilities against $\mathrm{T}$ cells was observed. Briefly, $\mathrm{T}$ cells were more proliferative, active and altered cytokine production when co-cultured with TAMs exposed to ATYR2810 compared to TAMs differentiated in its absence. Interestingly, we observed a significant decrease in ZEB1 gene and protein expression in ATYR2810 treated TAMs compared to non-treated TAMs. ATYR2810 also decreased the suppressive ability of TAMs when present in co-culture experiments. Conclusions We show here for the first time that ATYR2810, known to bind NRP2 tumor cells, can also bind and exert effects on human TAMs. Given the intricate relationship between TAMs and tumors, we believe that this novel finding provides additional insight into the mechanism of action of ATYR2810 as a potential immune regulator. We show for the first time that NRP2 has the ability to regulate ZEB1 expression in TAMs; reducing their suppressive nature, pointing to a novel role of NRP2 in TAMs. These findings indicate ATYR2810s potential to be an effective anti-cancer agent through regulation of ZEB1 in both TAMs and tumors.

\section{REFERENCES}

1. Caunt M, Mak J, Liang W-C, Stawicki S, Pan Q, Tong RK, Kowalski J, Ho C, Reslan HB, Ross J, Berry L, Kasman I, Zlot C, Cheng Z, Le Couter J, Filvaroff EH, Plowman G, Peale F, French D, Carano R, Koch AW, Wu Y, Watts RJ, TessierLavigne M, Bagri A. Blocking Neuropilin-2 function inhibits tumor cell metastasis. 2008;13(4):331-342. https://doi.org/10.1016/j.ccr.2008.01.029.

2. Roy S, Bag AK, Dutta S, Polavaram NS, Islam R, Schellenburg S, Banwait J, Guda C, Ran S, Hollingsworth MA, Singh RK, Talmage JE, Muders MH, Batra SK, Datta K. Macrophage-derived neuropilin-2 exhibits novel tumor-promoting functions. Cancer Res 2018;78(19):5600-5617. doi: 10.1158/0008-5472.CAN-18-0562.

3. Tyler S, Ferrer M, Polizzi C, Da Silva R, Eide L, Walwick K, Seikkula M, Burkart C, Paz $S$, Nangle L. Neuropilin-2 is expressed on immune cells present in the tumor microenvironment, and may contribute to the suppression of immune regulation leading to progression and metastasis of cancer. Keystone Symposia: Tumor Metabolism and the Microenvironment. 2021. https://www.atyrpharma.com/wpcontent/uploads/2021/01/Jan-2021-Keystone-Poster ST FINAL.pdf.

4. Xu Z, Burkart C, Goel HL, Rahman J, Polizzi C, Seikkula M, Burman L, Mercurio AM, Nangle LA. A domain-specific antibody to NRP2 down-regulated epithelialmesenchymanl transition genes and enhanced efficacy of stnadar-of-care therapeutics for aggressive breast cancer. American Society for Cancer Research, 2021. https://www.atyrpharma.com/wp-content/uploads/2021/04/2021Mar_AACR-poster_ZX_Final_v2.pdf.

5. Cortés M, Sanchez-Moral L, de Barrios O, Fernández-Aceñero MJ, Martínez-Campanario MC, Esteve-Codina A, Darling DS, Gyórffy B, Lawrence T, Dean, DC, Postigo A. Tumor-associated macrophages (TAMs) depend on ZEB1 for their cancerpromoting roles. EMBO 2017;36(22):3336-3355. doi: 10.15252/ embj.201797345. Epub 2017 Oct 16.

http://dx.doi.org/10.1136/jitc-2021-SITC2021.699 